\title{
Novel Co-processed Spray Dried Super Disintegrants Designing of Fast Dissolving Tablets Using
}

\author{
S. B. Shirsand, R. T.Gumate, V. J onathan and Shailashri \\ Department of Pharmaceutical Technology, H.K.E. Society's College of Pharmacy, \\ Sedam Road, Gulbarga- 585 105, India
}

(Received: February 22, 2016; Accepted: October 20, 2016; Published (web): December 27, 2016)

\begin{abstract}
In the present study, novel co-processed superdisintegrants were developed by spray drying method using microcrystalline cellulose and mannitol in different ratios (1:1, 1:2 and 1:3) for use in the fast dissolving tablet formulations. The developed excipients were evaluated for angle of repose, Carr's index and Hausner's ratio in comparison with physical mixture of superdisintegrants. The angle of repose of the developed excipients was found to be $<30^{\circ}$, Carr's index in the range of $9-15 \%$ and Hausner's ratio in the range of 1.12-1.16. Fast dissolving tablets of glibenclamide were prepared using the above co-processed superdisintegrants and evaluated for pre-compression and post-compression parameters. Based on in vitro dispersion time (approximately $22.23 \mathrm{sec}$ ), promising formulation $\mathrm{MCM}_{3}$ was tested for in vitro drug release pattern in $\mathrm{pH} 6.8$ phosphate buffer and stability (at $40{ }^{\circ} \mathrm{C} / 75$ $\%$ RH for 3 months), drug excipients interaction (IR spectroscopy) were studied. Among the designed formulations, the formulation $\left(\mathrm{MCM}_{3}\right)$ containing $8 \% \mathrm{w} / \mathrm{w}$ of co-processed superdisintegrant (1:3 mixture of microcrystalline cellulose and mannitol) emerged as the overall best formulation $\left(t_{50 \%} 1.6 \mathrm{~min}\right.$ ) based on drug release characteristics in $\mathrm{pH} 6.8$ phosphate buffer compared to commercial conventional tablet formulation ( $\left.\mathrm{t}_{50 \%} 6 \mathrm{~min}\right)$. Stability studies on promising formulation indicated that there were no significant changes in drug content and in vitro dispersion time $(\mathrm{p}<0.05)$.
\end{abstract}

Key words: Co-processed superdisintegrants, Spray drying, glibenclamide, fast dissolving tablets, microcrystalline cellulose, mannitol

\section{INTRODUCTION}

Major challenge for tablets and capsule manufacturing comes from the flow properties of the materials to be compressed. Most of the formulations $(>70 \%)$ contain excipients at higher concentration than active drug. ${ }^{1}$ In recent years drug formulation scientists have recognized that single-component excipients do not always provide the requisite performance to allow certain active pharmaceutical ingredients to be formulated or manufactured adequately. ${ }^{2}$ Hence, there is a need to have excipients with multiple characteristics built into them such as better flow, low/no moisture sensitivity, superior compressibility and rapid disintegration ability. ${ }^{3}$ One such approach for improving the functionality of excipients is co-processing of two or more excipients.

Correspondence to: S. B. Shirsand

Mobile: +919844079489 ; E-mail: shirsand@rediffmail.com

Dhaka Univ. J. Pharm. Sci. 15(2): 167-172, 2016 (December)
Co-processing is based on the novel concept of two or more excipients interacting at the sub particle level, the objective of which is to provide a synergy of functionality improvement as well as masking the undesirable properties of individual. ${ }^{4}$ Co-processing excipients leads to the formulation of excipient granules with superior properties compared with physical mixtures of components or individual components. $^{5}$ The concept of formulating fast dissolving tablets (FDT) of glibenclamide (antidiabetic $)^{6-10}$ using co-processed superdisintegrants which increase the water uptake with shortest wetting time and thereby decrease the disintegration time of the tablets by simple and cost effective (at low concentration of superdisintegrants) direct compression technique. 


\section{MATERIALS AND METHODS}

Glibenclamide (GLB) was gift samples from Cipla Ltd, MIDC patalganga (India). Directly compressible mannitol (Pearlitol SD 200), and microcrystalline cellulose (MCC, PH-102) were generous gifts from Strides Arcolabss, Bangalore (India). All the other chemicals used were of analytical reagent grade.

\section{METHODS}

Preparation of co-processed super disintegrants by spray drying method. Co-processed excipients were prepared by spray-drying technique using a laboratory spray dryer (Model SPD-P-111; Technosearch Instruments, India) with a standard 0.7 $\mathrm{mm}$ nozzle. Different batches of co-processed excipients were prepared by dissolving the different ratios of polymer MCC: mannitol in $(1: 1,1: 2$, and 1:3) dimethyl formamide (DMF) under constant stirring at $500 \mathrm{rpm}$ for $2 \mathrm{~h}$ using a magnetic stirrer. When the polymer dimethyl formamide (DMF) solution was fed to the nozzle with a peristaltic pump, the atomization occurred by the force of compressed air, disrupting the dimethyl formamide (DMF) solution into small droplets. The droplets, together with hot air, were blown into the drying chamber, where the solvent in the droplets was evaporated and discharged out through an exhaust tube. The co-processed excipients were collected and washed with distilled water to remove surface adhered drug and further dried completely in hot air oven at $40^{\circ} \mathrm{C}$ for $12 \mathrm{~h}$ and stored in a well-closed container. ${ }^{11}$

The processing conditions of the spray drying were:

Inlet Temperature: $165^{\circ} \mathrm{C}$

Outlet temperature: $120{ }^{\circ} \mathrm{C}$

Feed pump rate: $2 \mathrm{ml} / \mathrm{min}$

Spray pressure atomization: $2 \times 10^{5} \mathrm{PC}$.

Preparation of fast dissolving tablets by direct compression method. Fast dissolving tablets of GLB were prepared by direct compression method. All the ingredients were passed through \# 44-mesh separately. Then the ingredients were weighed and mixed in geometrical order and compressed into tablets of $150 \mathrm{mg}$ using $8 \mathrm{~mm}$ round flat punches on 10 -station rotary tablet machine (Clit). ${ }^{12}$

\section{Evaluation of fast dissolving tablets}

Weight variation. Twenty tablets were selected randomly from each formulation and weighed individually using a Shimadzu digital balance (BL$220 \mathrm{H})$. The individual weights were compared with the average weight for the weight variation. ${ }^{13}$

Thickness variation. Ten tablets from each formulation were taken randomly and their thickness was measured with a micrometer screw gauge.

Hardness and friability. Hardness of the tablets was measured using the Monsanto Hardness Tester (Pharmalab, Ahmedabad, India). The friability of a sample of twenty tablets was measured using a USP type Roche friabilator (Pharmalab, Ahmedabad, India). Pre-weighed tablets were placed in a plastic chambered friabilator attached to a motor revolving at a speed of $25 \mathrm{rpm}$ for $4 \mathrm{~min}$. The tablets were then dusted, reweighed and percentage weight loss (friability) was calculated.

Drug content uniformity. For the content uniformity test, ten tablets were weighed and pulverized to a fine powder, a quantity of powder equivalent to $5 \mathrm{mg}$ of GLB was extracted into methanol and liquid was filtered $(0.22 \mu \mathrm{m}$ membrane filter disc (Millipore Corporation). The GLB content was determined by measuring the absorbance at $227.85 \mathrm{~nm}$ (using UV-vis spectrophotometer, Shimadzu 1800) after appropriate dilution with methanol. The drug content was determined using standard calibration curve. The mean percent drug content was calculated as an average of three determinations. ${ }^{14}$

In vitro dispersion time. One tablet was placed in a beaker containing $10 \mathrm{ml}$ of $\mathrm{pH} 6.8$ phosphate buffer at $37 \pm 0.5^{\circ} \mathrm{C}$ and the time required for complete dispersion was determined. ${ }^{15}$

Wetting time and water absorption ratio ( $R$ ). Twice folded tissue paper was placed in a Petri dish having an internal diameter of $5 \mathrm{~cm}$ containing $6 \mathrm{ml}$ of water. A tablet was carefully placed on the surface of the tissue paper in the Petri dish. The time 
required for water to reach the upper surface of the tablet and to completely wet it was noted as the wetting time. Water absorption ratio $(\mathrm{R})$ was then determined according to the following equation:

$$
\mathrm{R}=100 \mathrm{x}\left(\mathrm{w}_{\mathrm{a}}-\mathrm{w}_{\mathrm{b}}\right) / \mathrm{w}_{\mathrm{b}}
$$

Where $w_{b}$ and $w_{a}$ were tablet weights before and after water absorption, respectively. ${ }^{16}$

In vitro drug release study. In vitro dissolution studies of the promising fast dissolving tablets of GLB, control and commercial conventional tablet formulations were performed according to USP XXIII Type-II dissolution apparatus (Electrolab, model TDT-06N) employing a paddle stirrer at 50 rpm using $900 \mathrm{ml}$ of $\mathrm{pH} 6.8$ phosphate buffer at $37 \pm 0.5^{\circ} \mathrm{C}$ as dissolution medium. One tablet was used in each test. Aliquots of the dissolution medium (5 $\mathrm{ml})$ were withdrawn at specific time intervals $(2,4,6$, $8,10,15 \& 30 \mathrm{~min}$ ) and replaced immediately with equal volume of fresh medium. The samples were filtered through $0.22 \mu \mathrm{m}$ membrane filter disc and analyzed for drug content by measuring the absorbance at $224.15 \mathrm{~nm}$. Drug concentration was calculated from the standard calibration curve and expressed as cumulative percent drug dissolved. The release studies were performed in replicates of three. ${ }^{17}$

Stability studies. The tablets of the promising formulation MCM3 were subjected to accelerated stability studies, by storing in amber colored rubber stopper glass vials at $40{ }^{\circ} \mathrm{C} / 75 \% \mathrm{RH}$ over a period of 3 months. At intervals of 1 month, the tablets were visually examined for any physical changes and evaluated for changes in drug content and in vitro dispersion time. Drug-excipients interaction were ruled out by FT-IR spectroscopic studies on the samples stored at the above conditions.

\section{RESULTS AND DISCUSSION}

Co-processed superdisintegrants were prepared by spray drying using microcrystalline cellulose and mannitol in different ratios $(1: 1,1: 2$. \& 1:3). The coprocessed superdisintegrants were evaluated for their flow and compression properties in comparison with physical mixture of superdisintegrants. The angle of repose of co-processed superdisintegrants was found to be $<30^{\circ}$ which indicate excellent flow in comparison to physical mixture of superdisintegrants $\left(>30^{\circ}\right)$ due to granule formation, Carr's index in the range of $9-15 \%$ and Hausner's ratio in the range of 1.12-1.16 (table 2).

Fast dissolving tablets of GLB were prepared using above co-processed superdisintegrants prepared by spray drying method and physical mixture of superdisintegrants. Directly compressible mannitol (Pearlitol SD 200) was used as a diluent to enhance mouth feel. A total of seven formulations and control formulation $\mathrm{CP}_{0}$ (without superdisintegrant) were designed. As the blends were free flowing (angle of repose $<30^{\circ}$ and Carr's index $<15 \%$ Table 3 ), tablets obtained were of uniform weight (due to uniform die fill), with acceptable variation as per IP specification i.e., below $7.5 \%$. Drug content was found to be in the range of 99.18 to $99.87 \%$, which is within acceptable limits. Hardness of the tablets was found to be in the range of $2.56-3.1 \mathrm{~kg} / \mathrm{cm}^{2}$. Friability below $1 \%$ was an indication of good mechanical resistance of the tablets. Water absorption ratio and wetting time, which are important criteria for understanding the capacity of disintegrants to swell in presence of little amount of water were found to be in the range of $44.7-75.33 \%$ and $20.29-105 \mathrm{sec}$ respectively.

Overall, the formulation $\mathrm{MCM}_{3}$ containing $8 \%$ w/w of co-processed superdisintegrant (1:3 mixture of microcrystalline cellulose and mannitol) was found to be promising and has shown an in vitro dispersion time of $22.23 \mathrm{sec}$, wetting time of 20.29 sec and water absorption ratio of $75.33 \%$ when compared to the formulation $\mathrm{PMCM}_{3}$ containing $8 \%$ $\mathrm{w} / \mathrm{w}$ of physical mixture of superdisintegrant (1:3 mixture of microcrystalline cellulose and mannitol) which shows $42.4 \mathrm{sec}, 40.33 \mathrm{sec}, 65 \%$ and control formulation $\left(\mathrm{CP}_{\mathrm{O}}\right)$ which shows $99 \mathrm{sec}, 105 \mathrm{sec}$ and $45 \%$ values respectively for the above parameters (Table 4).

In vitro dissolution studies on the promising formulation $\mathrm{MCM}_{3}$, control $\left(\mathrm{CP}_{0}\right)$ and commercial conventional formulations (CCF) were carried out in $\mathrm{pH} 6.8$ phosphate buffer, and the various dissolution 
Table 1. Formulations of glibenclamide fast dissolving tablet prepared by direct compression method.

\begin{tabular}{lccccccc}
\hline Ingredient & \multicolumn{7}{c}{ Formulation code } \\
\cline { 2 - 8 }$(\mathrm{mg})$ & $\mathrm{CP}_{0}$ & $\mathrm{PMCM}_{1}$ & $\mathrm{PMCM}_{2}$ & $\mathrm{PMCM}_{3}$ & $\mathrm{MCM}_{1}$ & $\mathrm{MCM}_{2}$ & $\mathrm{MCM}_{3}$ \\
\hline Glibenclamide & 5 & 5 & 5 & 5 & 5 & 5 & 5 \\
Co-processed excipients & - & 12 & 12 & 12 & 12 & 12 & 12 \\
Aspartame & 3 & 3 & 3 & 3 & 3 & 3 & 3 \\
Sodium stearyl fumarate & 1.5 & 1.5 & 1.5 & 1.5 & 1.5 & 1.5 & 1.5 \\
Talc & 3 & 3 & 3 & 3 & 3 & 3 & 3 \\
Pine apple flavour & 1.5 & 1.5 & 1.5 & 1.5 & 1.5 & 1.5 & 1.5 \\
Microcrystalline cellulose (Avicel PH-102) & 30 & 30 & 30 & 30 & 30 & 30 & 30 \\
Mannitol (Pearlitol SD 200) & 106 & 94 & 94 & 94 & 94 & 94 & 94 \\
Total weight & 150 & 150 & 150 & 150 & 150 & 150 & 150 \\
\hline
\end{tabular}

PM - Physical mixture of microcrystalline cellulose and mannitol in different ratios (1:1, 1:2, 1:3), MC- co-processed superdisintegrants of microcrystalline cellulose and mannitol in different ratios (1:1, 1:2, 1:3), CPo-Control formulation (without superdisintegrants).

Table 2. Pre-compression parameters of co-processed super disintegrants and physical mixture of super disintegrants.

\begin{tabular}{lcccccc}
\hline \multirow{2}{*}{\multicolumn{1}{c}{ Parameters }} & \multicolumn{7}{c}{ Formulation code } \\
\cline { 2 - 7 } & $\mathrm{PMCM}_{1}$ & $\mathrm{PMCM}_{2}$ & $\mathrm{PMCM}_{3}$ & $\mathrm{MCM}_{1}$ & $\mathrm{MCM}_{2}$ & $\mathrm{MCM}_{3}$ \\
\hline Bulk density (g/cc) & 0.42 & 0.44 & 0.43 & 0.43 & 0.46 & 0.44 \\
Tapped density (g/cc) & 0.47 & 0.48 & 0.48 & 0.50 & 0.55 & 0.49 \\
Angle of repose (degree) & 28.75 & 27.95 & 29.94 & 29.92 & 27.32 & 29.94 \\
Carr's index (percent) & 10.63 & 8.33 & 11.65 & 14.0 & 13.14 & 9.10 \\
Hausner's Ratio & 1.11 & 1.09 & 1.13 & 1.16 & 1.11 & 1.10 \\
\hline
\end{tabular}

Table 3. Pre-compression parameters of glibenclamide fast dissolving tablet formulations.

\begin{tabular}{lcccccc}
\hline \multirow{2}{*}{\multicolumn{1}{c}{ Parameters }} & \multicolumn{5}{c}{ Formulation code } \\
\cline { 2 - 7 } & $\mathrm{PMCM}_{1}$ & $\mathrm{PMCM}_{2}$ & $\mathrm{PMCM}_{3}$ & $\mathrm{MCM}_{1}$ & $\mathrm{MCM}_{2}$ & $\mathrm{MCM}_{3}$ \\
\hline Bulk density (g/cc) & 0.38 & 0.36 & 0.41 & 0.21 & 0.22 & 0.27 \\
Tapped density (g/cc) & 0.44 & 0.41 & 0.47 & 0.24 & 0.25 & 0.30 \\
Angle of repose (degree) & 28.71 & 27.90 & 29.94 & 29.92 & 27.26 & 29.93 \\
Carr's index (percent) & 13.63 & 12.19 & 12.76 & 12 & 12 & 10 \\
Hausner's Ratio & 1.15 & 1.13 & 1.14 & 1.14 & 1.13 & 1.11 \\
\hline
\end{tabular}

Table 4. Evaluation of glibenclamide fast dissolving tablet formulations.

\begin{tabular}{|c|c|c|c|c|c|c|c|}
\hline \multirow{2}{*}{ Parameters } & \multicolumn{7}{|c|}{ Formulation code } \\
\hline & $\mathrm{CP}_{0}$ & $\mathrm{PMCM}_{1}$ & $\mathrm{PMCM}_{2}$ & $\mathrm{PMCM}_{3}$ & $\mathrm{MCM}_{1}$ & $\mathrm{MCM}_{2}$ & $\mathrm{MCM}_{3}$ \\
\hline Hardness $\left(\mathrm{kg} / \mathrm{cm}^{2}\right)^{*} \pm \mathrm{SD}$ & $2.86 \pm 0.5$ & $2.9 \pm 0.10$ & $2.73 \pm 0.05$ & $2.56 \pm 0.05$ & $3.1 \pm 0.10$ & $3.0 \pm 0.10$ & $2.6 \pm 0.15$ \\
\hline Friability (\%) & 0.49 & 0.57 & 0.59 & 0.62 & 0.56 & 0.60 & 0.61 \\
\hline Thickness* (mm) & $3.37 \pm 0.22$ & $3.35 \pm 0.26$ & $3.58 \pm 0.07$ & $3.69 \pm 0.13$ & $3.40 \pm 0.16$ & $3.59 \pm 0.09$ & $3.55 \pm 0.43$ \\
\hline $\begin{array}{l}\text { In vitro dispersion time } \\
(\mathrm{s})^{*} \pm \mathrm{SD}\end{array}$ & $99 \pm 2$ & $57.66 \pm 2.51$ & $48.66 \pm 1.52$ & $42.4 \pm 2.50$ & $43.66 \pm 1.52$ & $37.0 \pm 2.0$ & $22.23 \pm 1.95$ \\
\hline Wetting time $(\mathrm{s})^{*} \pm \mathrm{SDs}$ & $105 \pm 4.93$ & $52.10 \pm 1.0$ & $47.66 \pm 2.08$ & $40.33 \pm 1.5$ & $34.04 \pm 1.0$ & $29.66 \pm 1.52$ & $20.29 \pm 0.5$ \\
\hline $\begin{array}{l}\text { Water absorption ratio } \\
(\%)^{*} \pm \mathrm{SD}\end{array}$ & $45 \pm 1$ & $44.7 \pm 1.53$ & $57.66 \pm 2.51$ & $65 \pm 1$ & $66.66 \pm 3.2$ & $70.66 \pm 0.57$ & $75.33 \pm 1.15$ \\
\hline $\begin{array}{l}\text { Percent drug content }(\%) * \\
\pm \text { SD }\end{array}$ & $99.28 \pm 1.52$ & $99.18 \pm 1.57$ & $99.28 \pm 2.02$ & $99.30 \pm 1.04$ & $99.45 \pm 1.01$ & $99.56 \pm 2.0$ & $99.87 \pm 0.07$ \\
\hline Weight variation (\%) & \multicolumn{7}{|c|}{$141-158 \mathrm{mg}$ (IP limits $\pm 7.5 \%)$} \\
\hline
\end{tabular}

* Average of 3 determinations. 
Table 5. In vitro dissolution parameters in ph 6.8 phosphate buffer.

\begin{tabular}{lccccccc}
\hline \multirow{2}{*}{ Parameters } & \multicolumn{7}{c}{ Formulation code } \\
\cline { 2 - 7 } & $\mathrm{D}_{5}$ & $\mathrm{D}_{10}$ & $\mathrm{D}_{15}$ & $\mathrm{t}_{50 \%}$ & $\mathrm{t}_{70 \%}$ & $\mathrm{t}_{90 \%}$ & $\mathrm{DE}_{10 \min }$ \\
\hline $\mathrm{CP}_{0}$ & $22.5 \%$ & $48.14 \%$ & $61.45 \%$ & $10.8 \mathrm{~min}$ & $18.6 \mathrm{~min}$ & $>30 \mathrm{~min}$ & $23.57 \%$ \\
$\mathrm{CCF}$ & $39 \%$ & $66.66 \%$ & $78.34 \%$ & $6 \mathrm{~min}$ & $11.8 \mathrm{~min}$ & $30 \mathrm{~min}$ & $35.84 \%$ \\
$\mathrm{PMCM}_{3}$ & $52 \%$ & $78.28 \%$ & $88.39 \%$ & $4.6 \mathrm{~min}$ & $8.2 \mathrm{~min}$ & $18 \mathrm{~min}$ & $49.23 \%$ \\
$\mathrm{MCM}_{3}$ & $76.5 \%$ & $90.25 \%$ & $99.33 \%$ & $1.6 \mathrm{~min}$ & $3.4 \mathrm{~min}$ & $10 \mathrm{~min}$ & $68.80 \%$ \\
\hline
\end{tabular}

$\mathrm{CP}_{0}$ is control formulation, $\mathrm{MCM}_{3}$ is promising fast dissolving tablet formulation, $\mathrm{PMCM}_{3}$ is formulation containing physical mixture of superdisintegrants in 1:3 ratio, CCF is conventional commercial tablet formulation, $\mathrm{D}_{5}$ is percent drug released in $5 \mathrm{~min}, \mathrm{D}_{10}$ is percent drug release in $10 \mathrm{~min}, \mathrm{D}_{15}$ is percent drug release in $15 \mathrm{~min}, \mathrm{DE}_{10 \min }$ is dissolution efficiency at $10 \mathrm{~min}, \mathrm{t}_{50 \%}$ is time for $50 \%$ drug dissolution, $\mathrm{t}_{70 \%}$ is time for $70 \%$ drug dissolution, $\mathrm{t}_{90} \%$ is time for $90 \%$ drug dissolution.

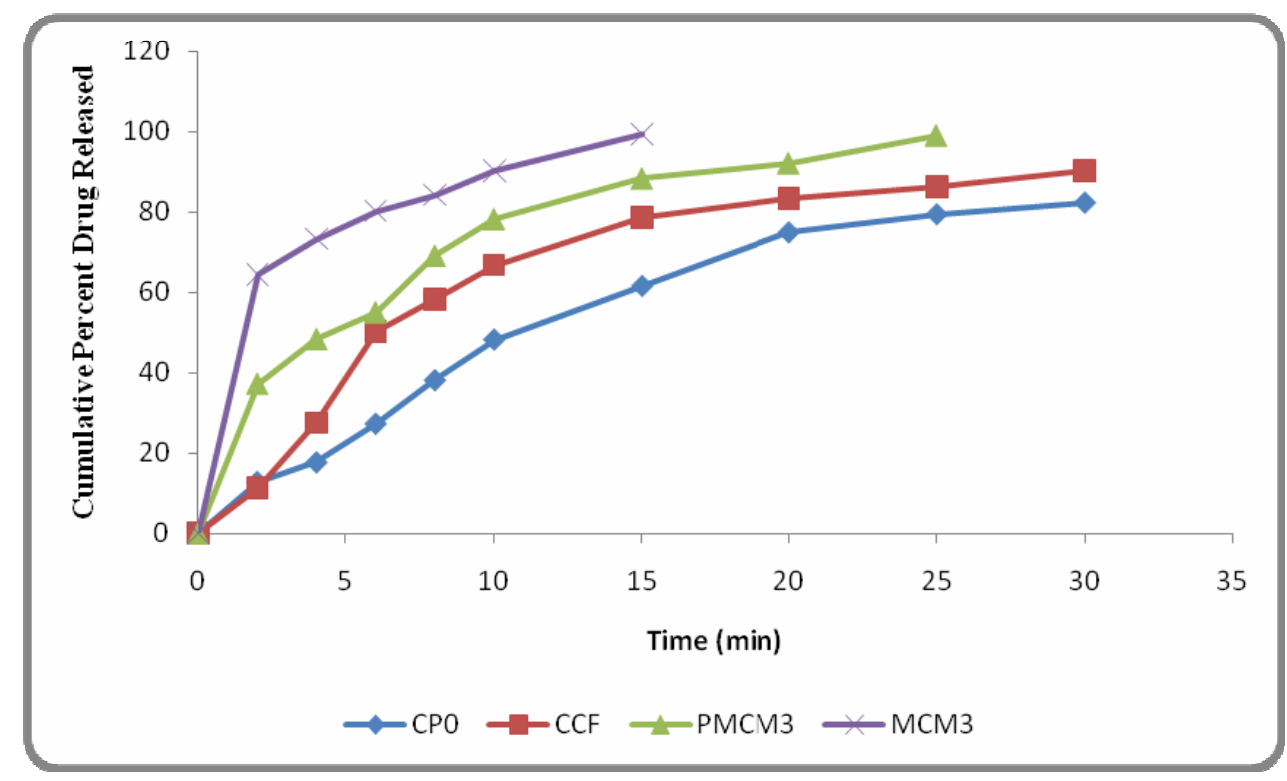

Figure 1. Dissolution rate profiles of (- -) control formulation (- - ) conventional commercial formulation (- - -) formulation containing $1: 3$ physical mixture of microcrystalline cellulose and mannitol (-- --$)$ promising formulation in $\mathrm{pH} 6.8$ phosphate buffer.

parameter values viz., percent drug dissolved in 5, 10 and $15 \min \left(\mathrm{D}_{5}, \mathrm{D}_{10}\right.$ and $\left.\mathrm{D}_{15}\right)$, dissolution efficiency at $10 \mathrm{~min}\left(\mathrm{DE}_{10} \mathrm{~min}\right), \mathrm{t}_{50 \%}, \mathrm{t}_{70 \%}$ and $\mathrm{t}_{90 \%}$ are shown in Table 5 and dissolution profile depicted in figure 1. This data reveals that overall, the formulation $\mathrm{MCM}_{3}$ has shown nearly four fold faster drug release $\left(\mathrm{t}_{50 \%}\right.$ $1.60 \mathrm{~min}$ ) when compared to the commercial conventional tablet formulation of GLB ( $\mathrm{t}_{50 \%} 6 \mathrm{~min}$ ).

IR spectroscopic studies indicated that the drug is compatible with all the excipients. The IR spectrum of $\mathrm{MCM}_{3}$ showed all the characteristic peaks of GLB pure drug, thus confirming that no interaction of drug occurred with the components of the formulation. Stability studies of the above formulations indicated that there are no significant changes in drug content and in vitro dispersion time at the end of 3 months period $(\mathrm{p}<0.05)$.

\section{CONCLUSION}

Co-processed superdisitegrants prepared by spray drying method consisting of microcrystalline cellulose and mannitol exhibited good flow and compression characteristics. GLB tablets containing co-processed superdisintegrants exhibited quick disintegration and improved drug dissolution. It can be concluded from the present work that coprocessed superdisintegrants of microcrystalline 
cellulose and mannitol are superior to physical mixture of microcrystalline cellulose and mannitol used in GLB fast dissolving tablets.

\section{ACKNOWLEDGEMENTS}

The authors are thankful to Cipla Ltd, MIDC patalganga Dist: Raigad (India) for providing gift sample of Glibenclamide. They also wish to express their gratefulness to the Principal, HKES's College of Pharmacy, Gulbarga for providing the necessary facilities for the study.

\section{REFERENCES}

1. York, P. 1992. Crystal engineering and particle design for the powder compaction process. Drug. Dev. and Ind. Pharm. 18, 677-721.

2. Block, L.H. 2009. Co-processed excipients. Pharmacopeial. Forum. 35, 1026-1028.

3. Avachat, A. and Ahire, V.J. 2007. Characterization and evaluation of spray dried co-processed excipients and their application in solid dosage forms. Indian. J. Pharm. Sci. 69, 85-90.

4. Reimerdes, D. 1993. The near future of tablet excipients. Manuf. Chem. 64, 14-15.

5. Jacob, S., Shirwaikar A.A., Joseph, A. and Srinivasan, K. 2007. Novel co-processed excipients of mannitol and microcrystalline cellulose for preparing fast dissolving tablets of Glipizide. Indian. J. Pharm. Sci. 69, 633-639.

6. Government of India Ministry of Health \& Family Welfare. Indian Pharmacopoeia. 2010. Delhi: Controller of Publications. p. 847-849.

7. British pharmacopoeia. 2009. London: The Stationary Office. 1, 2757-2760.
8. O’Neil, MJ., Smith, A., Heckelman, P.E., Obenchain, JR., Gallipeau, A.R. and D'Arecca, MA. 2006. The merck index: An encyclopedia of chemicals, drug and biologicals. $14^{\text {th }}$ ed. USA: Merck \& CO, INC. p. 4478.

9. Sweetman, SC., Martindale 2007: The Complete Drug Reference. $35^{\text {th }}$ ed. (volume-1) Great Britain: Pharmaceutical Press. p. 398.

10. Tripathi KD 2008. Essential of Medical Pharmacology. $6^{\text {th }}$ ed. New Delhi: Jaypee Brothers Medical Publishers (P) Ltd., pp. 266-274.

11. T. Tripathy and R. P. Singh. 2000. High performance flocculating agent based on partially hydrolysed sodium alginate-g-polyacrylamide. Eur. Polym. J. 36, 1471.

12. Kuchekar, B.S., Badhan, A.C. and Mahajan HS. 2004. Mouth dissolving tablets of salbutamol sulphate: A novel drug delivery system. Indian. Drugs. 41, 592-598.

13. Bankar, G.S., Anderson, N.R. Tablets. In: Lachman L, Lieberman H.A. and Kanig JL. 1987, editor. The Theory and Practice of Industrial Pharmacy. $3^{\text {rd }}$ ed., Mumbai: Varghese Publishing House, pp. 293-299.

14. Indian Pharmcopoeia 1996: New Delhi: Controller of Publication, Government of India; pp. 735-736.

15. Bi, Y.X., Sunada, H., Yonezawa, Y. and Danjo, K. 1999. Evaluation of rapidly disintegrating tablets by direct compression method. Drug. Develop. Ind. Pharm. 25, 571581.

16. Chaudhari, P.D., Chaudhari, S.P., Kohle, S.R., Dave, K.V. and More, D.M. 2005. Formulation and evaluation of fast dissolving tablets of famotidine. Indian. Drug. 42, 641-9.

17. Bhagwati, S.T., Hiremath, SN. and Sreenivas, S.A. 2005. Comparative evaluation of disintegrants by formulating cefixime dispersible tablets. Indian. J. Pharm. Edu. Res. 39, 194-197. 